\title{
Exploratory meta-analysis on deep brain stimulation in treatment-resistant depression
}

Smith DF. Exploratory meta-analysis on deep brain stimulation in treatment-resistant depression.

Objective: Deep brain stimulation is currently an experimental treatment for major depressive disorder. Information is lacking, however, on how sham responding may affect efficacy. This article applies exploratory meta-analysis to address that topic.

Methods: Data on benefits of deep brain electrical stimulation come from a recent review. Stimulated brain regions included subgenual cingulate, capsular interna, nucleus accumbens, and medial forebrain bundle. Expert opinion plus random number software was used to generate hypothetical values for sham responding.

Results: An effect size of 1.71 (95\% CI: 1.47-1.96) was obtained for deep brain stimulation versus sham treatment in patients suffering from long-term treatment-resistant depression.

Conclusion: Preliminary findings on deep brain electrical stimulation suggest that the procedure may be $71 \%$ more effective than sham treatment. Expressing these findings as patients-needed-to-treat, deep brain electrical stimulation is required by 2.9 patients with long-term treatment-resistant depression in order for one of them to benefit.

\author{
Donald F. Smith \\ Institute for Clinical Medicine, Translational \\ Neuropsychiatry Unit, Psychiatric Hospital of \\ Aarhus University, Risskov, Denmark
}

Keywords: affective disorder; deep brain stimulation; depression; treatment resistance

Donald F. Smith, Institute for Clinical Medicine, Translational Neuropsychiatry Unit, Psychiatric Hospital of Aarhus University, Risskov, Denmark. Tel: +45-78463026;

Fax: +45-78461662;

E-mail: dfsmithdfsmith@gmail.com

Accepted for publication August 19, 2014

First published online September 18, 2014

\section{Significant outcomes}

- This exploratory meta-analysis showed a statistically significant effect in favour of deep brain stimulation in treatment-resistant major depressive disorder.

- In terms of patients-needed-to-treat, the results show that one out of three patients with long-term treatment-resistant depression can be expected to benefit from deep brain electrical stimulation.

\section{Limitation}

- Estimates of sham responding to deep brain stimulation are derived by expert opinion rather than by properly controlled clinical trials.

\section{Introduction}

Direct electrical stimulation in the brain continues to attract much attention for relief of treatment-resistant depression (1,2). There is, however, still great uncertainty concerning efficacy, due in part to lack of information on sham responding to the intensive selection and surgical procedures (3). In the absence 
DBS for TRD

Table 1. Summary of data used for an exploratory meta-analysis on benefit of deep brain electrical stimulation in patients with long-term treatment-resistant depression

\begin{tabular}{|c|c|c|c|c|c|c|}
\hline Study (Reference number) & Anatomical site & $\begin{array}{l}\text { Number of } \\
\text { patients }\end{array}$ & $\begin{array}{c}\text { Responders } \\
(\%)\end{array}$ & $\begin{array}{c}\text { Random estimate of sham } \\
\text { response }(\%)\end{array}$ & $\begin{array}{l}\text { Estimate of } \\
\text { effect size }\end{array}$ & $\begin{array}{l}\text { Estimate of } \\
95 \% \mathrm{Cl}\end{array}$ \\
\hline Kennedy et al. (11) & Subgenual cingulate & 20 & 55 & 14 & 2.02 & $1.89-2.14$ \\
\hline Puigdemont et al. (12) & Subgenual cingulate & 8 & 62.5 & 18 & 2.03 & $1.92-2.14$ \\
\hline Holtzheimer et al. (13) & Subgenual cingulate & 10 & 43 & 10 & 1.92 & $1.76-2.07$ \\
\hline Lozano et al. (14) & Subgenual cingulate & 21 & 29 & 18 & 0.62 & $0.50-0.74$ \\
\hline Malone (6) & Anterior limb of capsula interna & 17 & 53 & 14 & 1.94 & $1.81-2.06$ \\
\hline Dougherty et al. (15) & Anterior limb of capsula interna & 30 & 21 & 15 & 0.41 & $0.27-0.55$ \\
\hline Bewernick et al. (16) & Nucleus accumbens septi & 13 & 45 & 11 & 1.89 & $1.75-2.03$ \\
\hline Schlaepfer et al. (17) & $\begin{array}{l}\text { Supero-lateral branch of the } \\
\text { medical forebrain bundle }\end{array}$ & 6 & 85 & 23 & 2.94 & $2.81-3.08$ \\
\hline
\end{tabular}

The information in the first three columns is summarised from a very recent review (2). The estimates of sham response were obtained by expert opinion plus random number software (http://www.random.org/integers/) (see 'Materials and methods' section).

of such information, we cannot establish the likelihood of success of the intervention. There are, however, ways of estimating the likelihood of sham responding in certain situations (4). Here, expert opinion is applied to gain an understanding of the potential role of sham responding in the efficacy of deep brain stimulation in patients suffering from long-term treatment-resistant depression.

\section{Materials and methods}

Information on the likelihood of sham responding in patients with long-term treatment-resistant depression was solicited from three eminent colleagues (Helen Mayberg, Donald A. Malone Jr., and Thomas E. Schlaepfer) with extended experience using deep brain stimulation for psychiatric disorders (5-7). The information that they supplied along with the present authors' understanding of treatment-resistant depression (8) placed the likelihood of sham responding in the range $10-25 \%$. Using random number software (http://www.random.org/integers/), nine values were generated and were applied consecutively to the data provided by a recent review on deep brain stimulation in long-term treatment-resistant depression (Table 1) (2).

\section{Results}

Effect sizes were too heterogeneous to uphold a fixed effects model $(Q=36.2$, df $=7, p<0.01)$ (9). Therefore, a random effects model was used, and it provided an estimate of effect size of 1.71 (95\% CI: $1.47-1.96 ; Z=13.6$, df $=7, p<0.01$ ) for deep brain stimulation versus sham treatment in patients with long-term treatment-resistant depression. In the present context, an effect size of 1.71 means that deep brain stimulation was $71 \%$ more likely than sham treatment to be of benefit for patients with longterm treatment-resistant depression.

\section{Discussion}

The present exploratory finding can be expressed in terms of patients-needed-to-treat (10). Assuming a sham response rate of $20 \%$ to the intensive selection and surgical procedures required by deep brain stimulation, then we can expect 2 out of 10 patients to report some benefit even in the absence of electrical stimulation. The estimate of effect size derived by the present exploratory meta-analysis indicates that, in addition to sham responding, another 1.4 patients (i.e. sham response $\times 0.71$ ) can be expected to benefit from electrical stimulation. Thus, for every 2.9 patients (10/3.4) with long-term treatment-resistant depression receiving deep brain electrical stimulation, one can be expected to benefit. Whether this level for patients-needed-to-treat is viewed as large or small is, of course, a matter of opinion.

A shortcoming of the present analysis relates to the current lack of empirical evidence on the level of sham responding to deep brain non-stimulation in patients with long-term treatment-resistant depression. Information on that topic can be expected to come eventually from properly controlled, large-scale clinical trials that either disprove or confirm the present findings. One reviewer of this article noted that two presentations at recent conferences concerned as yet unpublished accounts on clinical trials on deep brain stimulation that were discontinued owing to no difference between active versus sham treatment in depressed subjects. Be that as it may, at least 10 additional clinical trials on deep brain stimulation in depressed subjects are currently underway, according to records available at clinicaltrials.gov. Perhaps the outcome of those studies, once published, can provide further insight concerning the ultimate value of sham 
versus active deep brain stimulation in treatmentresistant depression.

\section{Acknowledgements}

The author thanks Chief Physicist Søren B. Hansen for helpful comments. Helen Mayberg, Donald A. Malone Jr., and Thomas E. Schlaepfer have been informed about the content of this article. The author declares no conflict of interest. This work was done during the author's employment at Aarhus University.

\section{References}

1. Berlim MT, Mcgirr A, Van Den Eynde F, Fleck MP, GiacobBe P. Effectiveness and acceptability of deep brain stimulation (DBS) of the subgenual cingulate cortex for treatment-resistant depression: a systematic review and exploratory meta-analysis. J Affect Disord 2014;159: 31-38.

2. Schlaepfer TE, Bewernick BH, Kayser S, Hurlemann R, CoEnen VA. Deep brain stimulation of the human reward system for major depression-rationale, outcomes and outlook. Neuropsychopharmacology 2014;39:1303-1314.

3. Blumberger DM, Mulsant BH, Daskalakis ZJ. What is the role of brain stimulation therapies in the treatment of depression? Curr Psychiatry Rep 2013;15:368-378.

4. Merkl A, Schneider GH, Schonecker T et al. Antidepressant effects after short-term and chronic stimulation of the subgenual cingulate gyrus in treatment-resistant depression. Exp Neurol 2013;249:160-168.

5. Mayberg HS, Lozano AM, Voon V et al. Deep brain stimulation for treatment-resistant depression. Neuron 2005; 45:651-660.

6. MALONE DA JR. Use of deep brain stimulation in treatmentresistant depression. Cleve Clin J Med 2010;77(Suppl. 3): S77-S80.
7. Schlaepfer TE, Cohen MX, Frick C et al. Deep brain stimulation to reward circuitry alleviates anhedonia in refractory major depression. Neuropsychopharmacology 2008;33:368-377.

8. Smith DF, Stork BS, Wegener G et al. [11C]Mirtazapine binding in depressed antidepressant nonresponders studied by PET neuroimaging. Psychopharmacology (Berl) 2009; 206:133-140.

9. LiPSEY MW, WiLSON DB. Practical meta-analysis. Thousand Oaks, CA: Sage Publications Inc., 2001.

10. Connolly KR, Thase ME. If at first you don't succeed: a review of the evidence for antidepressant augmentation, combination and switching strategies. Drugs 2011;71:43-64.

11. Kennedy SH, Giacobbe P, Rizvi SJ et al. Deep brain stimulation for treatment-resistant depression: follow-up after 3 to 6 years. Am J Psychiatry 2011;168:502-510.

12. Puigdemont D, Perez-Egea R, Portella MJ et al. Deep brain stimulation of the subcallosal cingulate gyrus: further evidence in treatment-resistant major depression. Int $\mathbf{J}$ Neuropsychopharmacol 2012;15:121-133.

13. Holtzheimer PE, Kelley ME, Gross RE et al. Subcallosal cingulate deep brain stimulation for treatment-resistant unipolar and bipolar depression. Arch Gen Psychiatry 2012;69:150-158.

14. Lozano AM, Giacobbe P, Hamani $\mathrm{C}$ et al. A multicenter pilot study of subcallosal cingulate area deep brain stimulation for treatment-resistant depression. J Neurosurg 2012;116:315-322.

15. Dougherty DD, CARPenter LL, Bhati MT et al. A randomized sham-controlled trial of DBS of the VC/VS for treatmentresistant depression. 67th Annual Scientific Convention, Society of Biological Psychiatry, Philadelphia, PA. 2012.

16. Bewernick BH, Kayser S, Sturm V, Schlaepfer TE. Longterm effects of nucleus accumbens deep brain stimulation in treatment-resistant depression: evidence for sustained efficacy. Neuropsychopharmacology 2012;37:1975-1985.

17. Schlaepfer TE, Bewernick BH, Kayser S, Madler B, COENEN VA. Rapid effects of deep brain stimulation for treatment-resistant major depression. Biol Psychiatry 2013; 73:1204-1212. 